\title{
COMPARISON OF CARDIAC TROPONIN-I LEVELS IN POSTOPERATIVE PERIOD OF ON PUMP VERSUS OFF PUMP CORONARY ARTERY BYPASS SURGERY
}

\author{
Kifayat Ullah, Muhammad Waseem, Asif Mahmood Janjua, Shakila Khadim*, Mashood Shahid Amin, Muhammad \\ Ashfaq, Anum Mustafa
}

Armed Forces Institute of Cardiology/National Institute of Heart Disease (AFIC/NIHD)/National University of Medical Sciences (NUMS) Rawalpindi Pakistan, *National University of Medical Sciences (NUMS) Rawalpindi Pakistan

\begin{abstract}
Objective: To compare cardiac troponin-I levels in post-operative period of on-pump (ONCAB) versus off-pump coronary artery bypass surgery.

Study Design: Prospective Observational Study.

Place and Duration of Study: Armed Forces Institute of Cardiology, from Jan 2019 to Dec 2019.

Methodology: This prospective observational study was done at Armed Forces Institute of Cardiology from 1st January 2019 to 31 ${ }^{\text {st }}$ December 2019. Eighty six (43 in each on-pump and off-pump) patients admitted for elective coronary artery bypass grafting, aged 30-80 years were included in the study. Baseline data and cardiac troponin-I levels preoperatively as well as at 6, 12, 18 and 24 hours after the surgery in both groups were recorded and analyzed.

Results: Out of 100 patients, mean age of the patients was $57.59 \pm 10.24$ years and $85 \%$ were males. All the base line characteristics, comorbid conditions and intra-operative findings were identical in both groups. There was marked rise in CK-MB levels postoperatively in overall participants. There was significant rise in Troponin I levels postoperatively in overall participants. Compared to OPCAB, postoperative Troponin I at 6hours and 12hours was significantly higher in ONCAB.

Conclusion: Compared to OPCAB, postoperative Troponin I at 6 hours and 12-hours was significantly high in ONCAB. However, there was no gross discrepancy in postoperative Troponin I levels between OPCAB and ONCAB at 18- \& 24-hours after surgery.
\end{abstract}

Keywords: Coronary artery bypass grafting, Post-operative, On-pump, Off-pump, Troponin I.

This is an Open Access article distributed under the terms of the Creative Commons Attribution License (http://creativecommons.org/licenses/by/4.0), which permits unrestricted use, distribution, and reproduction in any medium, provided the original work is properly cited.

\section{INTRODUCTION}

Coronary artery bypass graft (CABG) surgery is a frequent cardiac surgery. In patients with coronary artery disease, revascularization of ischemic myocardial tissue prolongs survival ${ }^{1}$. Myocardial ischemia is induced by CABG surgery itself $^{2}$.

Until lately, creatinine kinase and its $\mathrm{MB}$ fraction $(\mathrm{CKMB})$ were used to identify injured myocardium, but after surgery, the specificity of this testalone to identify myocardial ischemia was uncertain ${ }^{3,4}$. Lately, troponins (cardiac markers) have gained popularity in identifying myocardial ischemia due to their high sensitivity and specificity for cardiac tissue ${ }^{5}$. By measuring troponin I levels, even smaller myocardial injury

Correspondence: Dr Kifayat Ullah, Adult Cardiac Surgery, AFIC/NIHD Rawalpindi Pakistan may be identified with higher diagnostic accuracy ${ }^{6}$. To stratify the risk in cases with acute coronary syndrome, troponin I was introduced chiefly as a sensitive biomarker?

Particular indications for OPCAB are still under debate. Lately, some studies did comparison between $\mathrm{ONCAB}$ and $\mathrm{OPCAB}$ procedures on random cases and observed relatable perioperative mortality and markedly low morbidity in OPCAB cases ${ }^{8}$. Supporters of OPCAB procedure are putting stress on the low inflammatory reaction and reduced myocardial ischemia. Many other studies reported a decrease in myocardial biomarkers in off-pump CABG patients indicating better myocardial protection 9,10 .

In Comparison betweenoff-pump CABG and ONCAB, these studies could not differentiate between myocardial ischemia caused by the $\mathrm{CPB}$. 
In cases suffering from acute myocardial injury, suggested procedure is performing CABG onpump beating heart with the intention of preserving natural coronary blood flow, emptying the heart and ensuring the proper organ perfusion ${ }^{11}$. Restricted clinical data showedan advantage of CPB-supported beating heart surgery in limitedhigh-risk cases ${ }^{12}$. However, on local grounds, limited data exists about theactual myocardial damage resulting from OPCAB or ONCAB. So, this study was planned to compare the post-operative results on the myocardial damage using troponin I levels inpatients who underwent either of the two procedures.

\section{METHODOLOGY}

This was conducted as prospective observational study at Armed Forces Institute of Cardiology, Rawalpindi, over a duration of one year from 1st January 2019 to 31st December 2019. Patients admitted for elective CABG, aged 30-80 years were included in the study after informed written consent. Patients undergoing re-operations, left main stenosis of $>70 \%$, ejection fraction of $<50 \%$ and combined cardiac procedures were excluded from the study. A minimum sample size of 86 (43 in each on-pump and off-pump) patients at power of $80 \%$ and $95 \%$ confidence level was calculated using cardiac troponin I (CTnI) at 12-hrs post-operatively in on-pump 2.1 \pm 1.9 versus off-pump $1.0 \pm 1.7$ reported in study from Bangladesh ${ }^{13}$, through OpenEpi software using formal for mean difference. Baseline data including age, gender, body surface area, status of smoking, diabetes and hypertension were noted. Operative data in the form of number of grafts, left internal mammary artery use, intraaortic balloon pump (IABP) used, cardiopulmonary bypass (CPB) time and aortic cross clamp time were noted. Cardiac troponin I (CTnI) levels were checked in venous blood samples of patients from both groups preoperatively and also at 6, 12, 18 and 24 hours of aortic unclamping in the ONCAB group and after the last distal anastomosis in OPCAB group. The CTnI levels were measured by an immunometric method. However, CK-MB levels were measured pre- operatively and once after shifting to ICU. All the patients were connected with an ECG monitor and a venous pressure monitor. Their central venous pressure was maintained. Intra-arterial radial cannula was also passed and attached to the monitor for nonstop pressure monitoring. Foley's catheter was also introduced in all patients for urine output and skin was prepared on chest, abdomen, groin and both legs. All the patients underwent median sternotomy and harvesting of great saphenous vein. For the pedicle graft internal mammary artery was prepared.

Leftanterior descending artery (LAD), diagonalbranches (D), right coronary artery (RCA) and Obtuse marginal (OM) branches were the primary target vessels in OPCABG group. In all the patients, after harvesting the arterial and venous grafts, $100 \mathrm{U} / \mathrm{kg}$ of heparin was infused before the distal anastomosis was done. Proximal \& distal anastomosis weremade in conventional surgery.

In ONCAB group, after harvesting of arterial and venous grafts, all patients received $300 \mathrm{U} / \mathrm{kg}$ of heparin. Using two staged venous cannulations in right atrium and aortic cannulation cardiopulmonary bypass was established. A flow of $2.5 \mathrm{~L} / \mathrm{m} / \mathrm{m}^{2}$ was maintained during $\mathrm{CPB}$ and myocardial preservation was achieved through intermittent antegrade hyperkalemic cold blood cardioplegia. All the patients remained in ICU after procedure.

Statistical analysis was performed with SPSS version 25.0. Values are expressed as median and range for quantitative variables and frequency and percentage for qualitative variables. Categorical data were compared with the $\chi^{2}$ test and quantitative variables, with the Mann-Whitney U-test. A $p$-value of $\leq 0.05$ was takenstatistically significant.

\section{RESULTS}

Over a period of one year, 100 patients underwent CABG either off-pump $(n=50)$ or onpump $(n=50)$. Mean age of the patients was 57.59 \pm 10.24 years and $85 \%(n=85)$ were males. Mean body surface area of the participants was $1.85 \pm$ 
$0.18 \mathrm{~m}^{2}$. Most common reason for the CABG was triple vessel coronary artery disease $76(76 \%)$ followed by double vessel disease in 14 (14\%). More than half of the participants were hypertensive $56(56 \%), 52(52 \%)$ were smoker and 34 $(34 \%)$ were diabetic patients (table-I).
ONCAB groups ( $p$-value 0.31 ). Median TroponinI levels $\mathrm{ng} / \mathrm{ml}$ in all participants were 0.021 (range $0.007-4.97$ ) and these were comparable in both the Off-pump vs. On-pump CABG (0.030 (0.014-4.97) vs. 0.020 (0.007-2.38), $p$-value 0.94). There was significant rise in CK-MB levels post-

Table-I: Characteristics of patients undergoing ONCAB $(n=50)$ versus OPCAB $(n=50)$ procedures.

\begin{tabular}{|c|c|c|c|c|}
\hline Characteristic & $\begin{array}{l}\text { Overall } \\
(n=100)\end{array}$ & $\begin{array}{c}\text { Off-pump } \\
\text { CABG }(n=50)\end{array}$ & $\begin{array}{c}\text { On-pump CABG } \\
(n=50)\end{array}$ & $\begin{array}{c}p- \\
\text { value* }\end{array}$ \\
\hline Age in years, Mean $\pm S D$ & $57.59 \pm 10.24$ & $59.48 \pm 9.76$ & $55.70 \pm 10.44$ & 0.65 \\
\hline \multicolumn{5}{|l|}{ Gender $n, \%$} \\
\hline Male & $85(85)$ & $42(84)$ & $43(86)$ & 0.78 \\
\hline Body surface Area & $1.85 \pm 0.18$ & $1.85 \pm 0.18$ & $1.86 \pm 0.17$ & 0.85 \\
\hline \multicolumn{5}{|l|}{ No. of Vessels Involved n (\%) } \\
\hline Double vessel & $14(14)$ & $10(20)$ & $04(08)$ & \multirow{3}{*}{0.06} \\
\hline Trippel vessel & $76(76)$ & $33(66)$ & $43(86)$ & \\
\hline Trippel vessel with LMS & $10(10)$ & $07(14)$ & $03(06)$ & \\
\hline \multicolumn{5}{|l|}{ Co-morbid Conditions, Yes n(\%) } \\
\hline Diabetes mellitus & $34(34)$ & $17(34)$ & $17(34)$ & 1.0 \\
\hline Hypertension & $56(56)$ & $28(56)$ & $28(56)$ & 1.0 \\
\hline Smoking & $52(52)$ & $28(56)$ & $24(48)$ & 0.42 \\
\hline \multicolumn{5}{|l|}{ Intra-operative Findings } \\
\hline $\begin{array}{l}\text { Number of grafts used (median, } \\
\text { range) }\end{array}$ & $3(1-4)$ & $3(1-4)$ & $3(1-4)$ & 0.63 \\
\hline LIMA used (Yes) n (\%) & $91(91)$ & $43(86)$ & $48(96)$ & 0.08 \\
\hline $\mathrm{CPB}$ time (minutes) mean $\pm \mathrm{SD}$ & - & - & $112.54 \pm 47.45$ & - \\
\hline IABP used (Yes) n (\%) & $2(2)$ & $1(2)$ & $1(2)$ & 1.0 \\
\hline $\begin{array}{l}\text { Aortic cross-clamp time (minutes) } \\
\text { Mean } \pm \text { SD }\end{array}$ & - & - & $69.26 \pm 35.32$ & - \\
\hline
\end{tabular}

Median number of grafts used were 3 ranging from 1-4. Left Internal mammary artery (LIMA) graft was utilized in $91(91 \%)$ of the patients and IABP was utilized in only two patients $(2 \%)$. In on-pump CABG, mean CPB time was $112.54 \pm 47.45$ minutes and mean aortic cross-clamp time was $69.26 \pm 35.32$ minutes. All the base line characteristics, comorbid conditions and intra-operative findings were similar in OPCAB versus ONCAB groups $(p$-value $>0.05)$ (table-I).

Pre-operative median CK-MB (U/L) levels in overall participants were 22 (range 12-60) and these levels were equal in both OPCAB versus operatively in overall participants ( $p$-value $<0.001$, Wilcoxon Signed Rank test). This rise in CK-MB was high in ONCAB compared to OPCAB but did not achieve statistical significance (34 (13-107) vs. 39 (21 -182) respectively, $p$ value 0.06$)$. There was significant rise in Troponin I levels post operatively in overall participants $(p-$ value $<0.001$, Friedman's two-way analysis of variance by Ranks). Compared to OPCAB, postoperative Troponin I at 6hours and 12-hours was significantly higher in ONCAB ( $p$-value $<0.001 \&$ 0.008 respectively). However, there was no statistically significant discrepancy in postoperative Troponin I levels between OPCAB and ONCAB 
at 18 - \& 24-hours ( $p$-value $0.069 \& 0.177$ respectively)(table-II). the dominance of off-pump CABG versus $\mathrm{CPB}$, in terms of decreasing morbidity and mortality

Table-II: Biochemical Markers of myocardial injury in patients undergoing ONCAB $(n=50)$ versus OPCAB $(n=50)$ procedures $(n=100)$.

\begin{tabular}{|c|c|c|c|c|}
\hline Biochemical marker & $\begin{array}{l}\text { Overall } \\
(n=100)\end{array}$ & $\begin{array}{c}\text { OPCAB } \\
(n=50)\end{array}$ & $\begin{array}{c}\text { ONCAB } \\
(n=50)\end{array}$ & $\begin{array}{c}p- \\
\text { value }^{* *}\end{array}$ \\
\hline \multicolumn{5}{|l|}{ Pre-operative levels* } \\
\hline CK-MB (U/L) & $22(12-60)$ & $22(12-60)$ & $22(12-40)$ & 0.31 \\
\hline Troponin I ng/ml & $0.021(0.007-4.97)$ & $0.030(0.014-4.97)$ & $0.020(0.007-2.38)$ & 0.94 \\
\hline \multicolumn{5}{|l|}{ Post-operative levels } \\
\hline CK-MB U/L & $38(13-182)$ & $34(13-107)$ & $39(21-182)$ & 0.06 \\
\hline $\begin{array}{l}\text { Troponin I at 6-hr } \\
(\mathrm{ng} / \mathrm{ml})\end{array}$ & $4.40(0.029-50.0)$ & $1.86(0.029-43.43)$ & $7.06(0.073-50.0)$ & $<0.001$ \\
\hline $\begin{array}{l}\text { Troponin I at 12-hr } \\
(\mathrm{ng} / \mathrm{ml})\end{array}$ & $3.65(0.092-49.91)$ & $2.24(0.092-50.0)$ & $4.95(0.30-50.0)$ & 0.008 \\
\hline $\begin{array}{l}\text { Troponin I at } 18-\mathrm{hr} \\
(\mathrm{ng} / \mathrm{ml})\end{array}$ & $3.05(0.036-50.0)$ & $2.14(0.036-50.0)$ & $4.14(0.29-50.0)$ & 0.069 \\
\hline $\begin{array}{l}\text { Troponin I at 24-hr } \\
\text { (ng/ml) }\end{array}$ & $2.79(0.067-50.0)$ & $1.93(0.067-50.0)$ & $3.42(0.09-50.0)$ & 0.177 \\
\hline
\end{tabular}

${ }^{*}$ Median with range, ${ }^{* *}$ Mann-Whitney $U$ test

\section{DISCUSSION}

Although the current consensus is in favor of OPCAB procedurewhile performing cardiac surgery, it always has been under discussion, which surgical procedure is more beneficial in terms of decreasing morbidity and mortality. With the rising need of surgery, one certain benefit of OPCAB is that surgery can be carried out at a low expense without the use of a CPB machine. Though, a main apprehension for performing OPCAB is the apparent struggle of making coronary anastomoses on the beating heart. This leads to higher risks of intraoperative myocardial injury and suboptimal effort of making anastomoses $^{14}$. Regardless of the method, major concern always remains to achieve complete revascularization because post-operative death rate and risk of peri-operative myocardial injury rises markedly in case of incomplete anastomoses of conduits ${ }^{15}$.

To determine the mechanics of myocardial ischemia related with surgery with or without CPB utilization, biochemical markers have been utilized very commonly. Recent studies suggest related with myocardial ischemia16. Decreased perfusion during $\mathrm{CPB}$ is also related to microembolism and inflammatory alterations which leads to loss of protection by blood-brain barrier, causing cerebral edema ${ }^{17}$. So, this study has been conducted to approve the past results and to identify whether there is any gross difference in acute post-operative myocardial injury between both groups.

The results of this study suggest that postoperatively, there was significant rise in Troponin I levels in overall participants ( $p$-value <0.001) but compared to OPCAB, postoperative Troponin I at 6hours and 12-hours was significantly high in ONCAB. However, there was no statistically significant difference in postoperative Troponin I levels between OPCAB and ONCAB at 18- \& 24hours after surgery.

It is vital to consider that in addition to $\mathrm{CPB}$, many factors are responsible in causing inflammatory changes, e.g. surgical trauma, ischemia and thrombin pathway activation ${ }^{18}$. Even surgery itself can cause cytokines induced inflammatory reactions. Therefore, as observed in this study, 
the increase in troponin I levels was nearly unchanging at 18- and 24-hours after surgery in both groups, with certain evidence of myocardial ischemia indicating consequence of surgery itself.

Our results are comparable to those by Bappu et al where they reported a significant increase in troponin-I levels from baseline,aftersix hours of surgery, but when observed at other time intervals, the discrepancy in levels between both groups was not significant ${ }^{19}$.

Contrary to results of our study, Badruzzaman et al, from Dhaka, Bangladesh reported lower levels of CTnI in patients who underwent off-pump CABG ${ }^{13}$. Rastan et al observed significantly high levels of CK-MB and troponin I from LIMA-LAD flow release onwards to four hours after surgery in the ONCAB compared to $\mathrm{OPCAB}^{20}$. Similarly, a study by Alwan et al showed that levels of cardiac troponin I were significantly high in the cardioplegic group at 6, 9, 12, and 24 hours compared to those in the beating heart group ${ }^{21}$.

Regarding inflammatory reaction, it is hard to derive an inference on the degree of myocardial ischemia depending on biochemical markers only, because many other confounding factors play role in regulating the actual hemostatic disturbances. The threshold for the release of inflammatory mediators is also regulated by individual risk stratification of the patient, administration regimen of heparin and protamine, anesthesiologic technique, and the proficiency of the surgeons involved in the surgery. Therefore, rise of troponin levels in this study does not particularly specify a direct relationship between the inflammatory reaction and the actual myocardial injury.

\section{CONCLUSION}

The findings of this study demonstrate that compared to OPCAB, postoperative Troponin I at 6-hours and 12-hours was significantly high in ONCAB. However, there was no marked discrepancy in postoperative Troponin I levels between $\mathrm{OPCAB}$ and $\mathrm{ONCAB}$ at 18- \& 24-hours after surgery. Further studies with larger sample size and more advanced markers of myocardial injury are suggested.

\section{CONFLICT OF INTEREST}

This study has no conflict of interest to be declared by any author.

\section{REFERENCES}

1. Ujueta F, Weiss EN, Shah B, Sedlis SP. Effect of percutaneous coronary intervention on survival in patients with stable ischemic heart disease. Curr Cardiol Rep 2017; 19(2): 17.

2. Wang $\mathrm{H}, \mathrm{Lyu} \mathrm{Y}$, Liao $\mathrm{Q}$, Jin $\mathrm{L}, \mathrm{Xu} \mathrm{L}, \mathrm{Hu} \mathrm{Y}$. Effects of remote ischemic preconditioning in patients undergoing off-pump coronary artery bypass graft surgery. Front Physiol 2019; 10(1): 495.

3. Bodor GS. Biochemical Markers of Myocardial Damage. J Int Fed Clin Chem 2016; 27(2): 95-111.

4. Domanski MJ. Prognostic implications of troponin $T$ and creatine kinase-MB elevation after coronary artery bypass grafting. Am Heart J 2012; 164(5): 636-37.

5. Vasile VC, Jaffe AS. High-sensitivity cardiac troponin for the diagnosis of patients with acute coronary syndromes. Curr Cardiol Rep 2017; 19(10): 92.

6. Lim CC, Cuculi F, van Gaal WJ, Testa L, Arnold JR, Karamitsos $\mathrm{T}$, et al. Early diagnosis of perioperative myocardial infarction after coronary bypass grafting: a study using biomarkers and cardiac magnetic resonance imaging. Ann Thorac Surg 2011; 92(6): 2046-53.

7. Neumann JT, Sörensen NA, Ojeda F, Renne T, Schnabel RB, Zeller $\mathrm{T}$, et al. Early diagnosis of acute myocardial infarction using high-sensitivity troponin I. PLoS One 2017; 12(3): e0174288.

8. Kowalewski M, Pawliszak W, Malvindi PG, Bokszanski MP, Perlinski D, Raffa GM, et al. Off-pump coronary artery bypass grafting improves short-term outcomes in high-risk patients compared with on-pump coronary artery bypass grafting: metaanalysis. J Thorac Cardiovasc Surg 2016; 151(1): 60-77.

9. Alwan K, Falcoz PE, Alwan J, Mouaand W, Oujaimi G, Chocron $S$, et al. Beating versus arrested heart coronary revascularization: evaluation by cardiac troponin I release. Ann Thorac Surg 2004; 77(1): 2051-55.

10. Dybdahl B, Wahba A, Haaverstad R, Kirkeby-Garstad I, Kierulf $\mathrm{P}$, Espevik T. On-pump versus off-pump coronary artery bypass grafting: more heat-shock protein 70 is released after on-pump surgery. Eur J Cardiothorac Surg 2004; 25(6): 985-92.

11. Xia L, Ji Q, Song K, Shen J, Shi Y, Ma R, et al. Early clinical outcomes of on-pump beating-heart versus off-pump technique for surgical revascularization in patients with severe left ventricular dysfunction: the experience of a single center. J Cardiothorac Surg 2017; 12(1): 11.

12. Erkut B, Dag O, Kaygin MA. On-pump beating-heart versus conventional coronary artery bypass grafting for revascularization in patients with severe left ventricular dysfunction: early outcomes. Can J Surg 2013; 56(6): 398-404.

13. Badruzzaman M, Hossain A, Adhikary AB, Quader SA, Kamal S, Saha SK. Evaluation of myocardial protection in off-pump vs on-pump coronary bypass surgery by troponin I estimation. Bangladesh Med Res Counc Bull 2010; 36(3): 93-96.

14. Møller CH, Penninga L, Wetterslev J, Steinbrüchel DA, Gluud C. Off-pump versus on-pump coronary artery bypass grafting for ischaemic heart disease. Cochrane Database Syst Rev 2012; 3(1): CD007224. 
15. Guerra M, Mota JC. Impact of incomplete surgical revascularization on survival. Interact Cardiovasc Thorac Surg 2012; 14(2): 176-82.

16. Hori D, Nomura Y, Ono M, Joshi B, Mandal K, Cameron D. Optimal blood pressure during cardiopulmonary bypass defined by cerebral autoregulation monitoring. J Thorac Cardiovasc Surg 2017; 154(5): 1590-98.

17. Bronicki RA, Hall M. Cardiopulmonary bypass-induced inflammatory response: pathophysiology and treatment. Pediatr Crit Care Med 2016; 17(8): S272-78.

18. Sato H, Yamamoto K, Kakinuma A, Nakata Y. Accelerated activation of the coagulation pathway during cardiopulmonary bypass in aortic replacement surgery: a prospective observa- tional study. J Cardiothorac Surg 2015; 10(1): 84.

19. Bappu NJ, Venugopal P, Bisoi AK, Mankad PS. Troponin-I release after cardiac surgery with different surgical techniques and post-operative neurological outcomes. Mcgill J Med 2006; 9(2): 88-94.

20. Rastan AJ, Bittner HB, Gummert JF, Walther T, Schewick CV, Girdauskas E. On-pump beating heart versus off-pump coronary artery bypass surgery evidence of pump-induced myocardial injury. Eur J Cardiothorac Surg 2005; 27(6): 1057-64.

21. Alwan K, Falcoz PE, Alwan J, Mouawad W, Oujaimi G, Chocron S. Beating versus arrested heart coronary revascularization: evaluation by cardiac troponin I release. Ann Thorac Surg 2004; 77(6): 2051-55. 